\title{
CLÚSTER: POTENCIADOR DEL DESARROLLO LOCAL
}

CLUSTER: LOCAL DEVELOPMENT POTENTIATOR

\author{
César Efraín Salvador Guerra, Mgtr. \\ Magíster en Economía mención en \\ Desarrollo Económico y Políticas Públicas (Ecuador). \\ Administrador de la Unidad Educativa Delfos, Ecuador. \\ cesalvador@delfos.edu.ec
}

\section{ARTÍCULO DE REFLEXIÓN}

Recibido: 22 de agosto de 2019.

Aceptado: 22 de noviembre de 2019.

\section{RESUMEN}

La clave para que los países alcancen el desarrollo radica en que sus economías dejen de depender del sector primario; a saber, de la agricultura y explotación de recursos no renovables; y que más bien, empiecen a transitar en los distintos sectores económicos tales como: secundario (manufactura), terciario (comercio, servicios) o cuaternario (I+D, innovación). Para que ello suceda, los países, regiones y localidades deben aprovechar el potencial de desarrollo con el que cuentan; de modo que, logren mejorar la calidad de vida y el bienestar económico de sus habitantes. Una manera de aprovechar esas potencialidades, es a través de la creación de clústers alrededor de un producto o servicio en particular. Esta investigación defiende la idea de que los clústers fomentan el desarrollo económico de las localidades donde operan.

Palabras clave: Desarrollo local, potencial de desarrollo, clústers, innovación.

\section{ABSTRACT}

The key for the countries to achieve their growth, lies in the fact to stop depending on the primary sector; namely, agriculture and non-renewable resources exploitation; and they better start testing through the different economic sectors, such as, secondary (manufacturing), tertiary (trade, services) or quaternary ( $R \& D$, innovation). To make this happen, countries, regions and local cities should take advantage of the development potential they have, so then they would improve the life style and the economic well-being of their inhabitants. One way to 
take advantage of these potentials is through the creation of clusters around a particular service or product. This research defends the idea that clusters promote the economic growth of the local cities where they operate.

Keywords: Local development, development potential, clusters, innovation.

\section{INTRODUCCIÓN}

A nivel mundial, los países considerados como desarrollados son aquellos que han logrado que sus economías escalen en los distintos sectores y pasen de depender de los sectores primario y secundario; es decir, de la extracción de recursos naturales como la agricultura, ganadería, minería, silvicultura y pesca, y de la manufactura y construcción respectivamente, a depender del sector terciario; a saber, de aquellas actividades como el comercio y la prestación de servicios. Incluso en algunos casos, debido al nivel de desarrollo que han alcanzado estos países, se habla de un sector cuaternario; es decir, actividades con un alto grado intelectual y de especialización como la investigación, el desarrollo y la innovación, la alta tecnología y la industria de la información.

En el caso del Ecuador del siglo XXI, este es un país cuya economía sigue dependiendo de la explotación de productos primarios, sean estos recursos naturales como el petróleo crudo; los cultivos permanentes como el mango, banano y plátano, cacao y café; los transitorios como el maíz duro y el arroz; la producción de madera de teca y palo de balsa; la floricultura; el cultivo de camarón y la pesca de atún.

Por décadas las economías de los distintos cantones del país han dependido del sector primario; de manera que, en la actualidad es común identificarlos con la producción específica de ciertos productos, por ejemplo: a Machala con el banano, a Milagro con las piñas, a Samborondón con el arroz, a Ambato con las flores, a Balzar con el maíz duro y al oriente ecuatoriano con el petróleo.

Si bien es cierto los ingresos por la comercialización y/o exportación de estos productos han aumentado - ya sea por el incremento de los precios o de la producción de los mismos - el verdadero crecimiento y desarrollo del Ecuador dependerá de cuán rápido cree industrias para procesar dichos productos, e implemente empresas proveedoras de insumos y equipos para dichas industrias. De modo que, el desarrollo del país dependa de la producción y 
comercialización de productos primarios y, de las distintas actividades que se formen y agrupen alrededor de estos, los clústers (Ramos, 1998).

La creación de un clúster alrededor de la producción y comercialización de un producto o servicio en particular potenciará el desarrollo a nivel local, permitiendo la mejora en la calidad de vida y el bienestar económico de los territorios donde operen.

Esta investigación pretende fundamentar los aspectos teóricos relacionados con el potencial de desarrollo territorial y los clústers, siendo este el método utilizado. Las variables de estudio fueron desarrollo local y clúster; considerándose como categorías de análisis en cuanto a desarrollo local a los recursos que conforman el potencial de desarrollo y a la innovación, la cual está vinculada al término clúster.

\section{REVISIÓN TEÓRICA}

\section{El Desarrollo Local en la Globalización}

Para entender el espacio que ocupa el desarrollo local en la globalización es necesario revisar, en primer lugar, el proceso de la globalización y el territorio como variable económica, a continuación, el desarrollo local en el contexto del proceso de la globalización, y luego, los enfoques sobre el desarrollo local.

\section{El proceso de globalización y el territorio como variable económica.}

A raíz de la crisis del modelo fordista, allá por la década de los años 70 , la acumulación capitalista a nivel mundial se agota y empieza a ser reemplazado por el modelo postfordista, también llamado modelo de acumulación flexible.

De modo que, el modelo de acumulación flexible se apunta como la nueva dinámica del proceso de globalización. Es así que, la globalización es un proceso histórico que ha pasado por varias etapas, siendo la más reciente revolución de las tecnologías de la información y las comunicaciones, la causante de economías cada vez más interdependientes y sensibles a lo que pasa en otros lugares del planeta.

Para Joseph Stiglitz, Premio Nobel de Economía 2001, la globalización es:

"La integración más estrecha de los países y los pueblos del mundo, producida por la enorme reducción de los costes de transporte y comunicación, y el desmantelamiento de las barreras artificiales a los flujos de bienes, servicios, capitales, conocimientos y (en menor grado) personas a través de las fronteras" (Stiglitz, 2002, p. 34). 
Además, "incluye aquellos procesos que contribuyen a intensificar la interacción humana en un amplio rango de contexto (económica, política, social, tecnológico, ambiental, entre otros) a través de las fronteras espacial, temporal y cognitiva que han separado a individuos y sociedades" (Moreno, 2009). Es otras palabras, esta globalización es multidimensional y va más allá de solo el aspecto económico.

Silva explica que este fenómeno multidimensional ha repercutido en: lo político por las competencias que recibe el Estado-Nación debido a "nuevos actores con poder", como los geomercados, las nuevas regiones supranacionales, las transnacionales, las redes, las ciudades-estados y las regiones-estado; lo productivo gracias al nuevo modelo flexible de alta tecnología y la crisis de las industrias manufactureras tradicionales; lo ecológico por el cambio climático y el deterioro de la capa de ozono debido a la industrialización y urbanización sobre la naturaleza; lo cultural en un doble impacto, por un lado la homogenización de las identidades y, por otro, el empoderamiento de la identidad local como referente de vida; del tiempo por el aumento de la velocidad en los procesos y el creciente ritmo de vida; del espacio debido a la miniaturización del mundo, la reducción de las barreras y las distancias gracias a los avances en las formas de transportación y las nuevas formas de comunicarse (2003, pág. 46).

Asimismo, Silva (2003) menciona que la globalización está ligada a la denominada "sociedad de la información y el conocimiento", gracias a los "importantes procesos de innovación tecnológica" que han permitido "significativos incrementos de productividad" y crecientes mejoras en la "competitividad" de las empresas (pág. 46). De modo que, "el conocimiento, es quizá el eje central de la globalización o de la fase tecnocognitiva del capitalismo y de la paulatina conformación de una sociedad del conocimiento" (Boisier, 2005).

Además, Boisier indica que existen "nuevas y complejas articulaciones entre conocimiento y territorio, que incluyen temas como innovación y territorio, aprendizaje colectivo, conocimiento tácito y codificado, surgimiento de regiones cognitivas (...) tales como regiones aprendedoras, regiones inteligentes, medios innovadores" (2005, pág. 50). Por tanto, el territorio - como variable económica - desempeña en la globalización un papel más importante que en el pasado.

León Segura citando a Garofoli (1992):

"El rasgo distintivo y característico del territorio es ser un factor estratégico de oportunidades de desarrollo y definidor de las características que el mismo puede asumir, 
(...) representa una agrupación de relaciones sociales, (...) el lugar donde la cultura local y los rasgos locales no transferibles se superponen; (...) donde el hombre y los negocios establecen relaciones; (...) instituciones públicas (estatales) y locales intervienen para la regulación social" (2011, p. 13).

Para Vázquez (1999) el territorio es un "agente de transformación y no un mero soporte de recursos y de las actividades económicas, ya que las empresas y los demás actores del territorio interactúan entre sí organizándose para desarrollar la economía y la sociedad del territorio" (p. 30).

De manera que, como indica León (2011), el territorio pasa de ser un actor pasivo a ser un actor principal de los procesos de acumulación de capital, constituyéndose en un "sistema vivo, orgánicamente estructurado, promotor o factor activo de desarrollo: que cuenta con un conjunto de recursos económicos, humanos, institucionales, culturales e intangibles" (p. 13).

Por su parte, Cividanes define el territorio como variable económica a la "unidad localizada de organización social endógena de los procesos de producción-reproducción de bienes públicos y activos empresariales especializados y específicos, articulada por estructuras en red y configurada por la evolutiva trayectoria histórica de asentamiento de un determinado sector industrial" (Cividanes, 2002).

Siendo la naturaleza económica del territorio la unidad localizada donde se organiza la interacción entre lo social, productivo e institucional para con eficacia y eficiencia realizar un determinado proceso productivo; por endógeno a la capacidad emprendedora necesaria para utilizar recursos internos y externos en el proceso productivo para generar valor o mayor rentabilidad; por especializados y específicos que en conjunto los bienes públicos y activos empresariales son competitivos en los mercados finales; es decir, que existe potencial dinámico en el sistema productivo local; por estructuras de red la forma en cómo se integran los agentes basándose en los principios de competencia del mercado, jerarquía, solidaridad, cooperación y representatividad que rigen en las empresas para defender sus propios intereses. Y finalmente, se entiende por trayectoria histórica evolutiva a que los sistemas productivos locales tienen la capacidad de cambiar y transformarse en el tiempo, lo cual les permite mantener una ventaja competitiva (Cividanes, 2002).

De modo que, el territorio dentro de la globalización cobra protagonismo al ser, no solo un soporte de recursos y actividades económicas sino también, un factor activo y decisivo del desarrollo al organizar los recursos económicos, humanos, institucionales, culturales e 
intangibles para mantener una ventaja competitiva que active la economía local y desarrolle la sociedad.

\section{EI Desarrollo local en el contexto del proceso de Globalización.}

En el contexto de este proceso de globalización lo local ha cobrado mayor relevancia en lo cultural, étnico, religioso e incluso en el ámbito del desarrollo, ya que desde lo local se puede lograr una mejora en la calidad de vida y en el bienestar económico (Alcañiz, 2008).

A partir de la década de los años 80 , el concepto de desarrollo local empieza a cobrar fuerza como medio para enfrentar la globalización; su objetivo es reactivar la economía creando nuevos empleos y mejorando el bienestar social a través del aprovechamiento de los recursos endógenos existentes.

Casanova define el desarrollo local como:

Proceso en el que una sociedad local, manteniendo su propia identidad y su territorio, genera y fortalece sus dinámicas económicas, sociales y culturales, facilitando la articulación de cada uno de estos subsistemas, logrando mayor intervención y control entre ellos. Para llevar adelante dicho proceso, es fundamental la participación de los agentes, sectores y fuerzas que interactúan dentro de los límites de un territorio determinado, los cuales deben contar con un proyecto común que combine: la generación de crecimiento económico, equidad, cambio social y cultural, sustentabilidad ecológica, enfoque de género, calidad y equilibrio espacial y territorial, con la finalidad de elevar la calidad de vida y el bienestar de sus pobladores (2004, p. 26).

Para Alcañiz Moscardó, el desarrollo local habla de estrategias impulsadas por los territorios desde "dentro" y desde "abajo"; es decir, un desarrollo endógeno que concede importancia no solo al capital, la tecnología y los recursos naturales, sino también a los activos intangibles como la información y los recursos humanos; en el cual es importante el diálogo social y la participación de los representantes locales, y que aprovecha las diferencias y particularidades culturales y físicas del territorio donde se implementa (2008, pp. 304-305).

Para la Organización Internacional del Trabajo (OIT), el desarrollo económico local fomenta "las ventajas comparativas y las características únicas de una localidad con el fin de fortalecer la economía local y crear empleo" (2019). Mientras que, Boisier define el desarrollo local como el "proceso endógeno registrado en pequeñas unidades territoriales y asentamientos humanos capaz de promover el dinamismo económico y la mejoría en la calidad de vida de la población" (2005, p. 52). 
De modo que, el desarrollo local es un proceso endógeno que busca mejorar la calidad de vida y alcanzar el bienestar económico de su población, aprovechando los recursos propios, la identidad cultural, el territorio y las características que lo distinguen - sus potencialidades para estimular el crecimiento económico, generar nuevos empleos y procurar la equidad y sostenibilidad ecológica.

Ahora bien, si la globalización es multidimensional al incluir lo económico, lo político, lo ecológico, lo cultural, lo tecnológico, así como el tiempo y espacio, además de estar ligada a la denominada "sociedad de la información y el conocimiento"; y el desarrollo local es el desarrollo - mejora en la calidad de vida y bienestar económico - que se produce en un determinado territorio gracias al aprovechamiento de las potencialidades e identidad cultural, existen tres posturas teóricas predominantes sobre cómo enfrentan las localidades esta problemática global-local (Alcañiz, 2008, p. 307):

- $\quad$ Como una amenaza que elimina las autonomías y a los actores locales que se resistan al proceso global.

- Como una alternativa para enfrentar la globalización; se otorga gran protagonismo a los actores locales.

- Como una oportunidad y un desafío de conjugar lo local con lo global, de explotar la globalización a favor del desarrollo local.

La globalización es un proceso que existe y es innegable, de ahí que debe ser considerada como una oportunidad para desarrollar lo local, de utilizar el mayor acceso a recursos globales como la tierra, el capital y los mercados que ahora existen para revalorizar los recursos endógenos. No obstante, se debe tomar en cuenta que no existe una única fórmula de insertar lo local en lo global, sino que el éxito dependerá de las características del territorio, los actores globales y las empresas; es decir, de cómo y por quién se llevará a cabo (Alcañiz, 2008).

De ahí que Boisier traduciendo del portugués a Buarque (1999) añade:

"El desarrollo local dentro de la globalización es una resultante directa de la capacidad de los actores y de la sociedad local para estructurarse y movilizarse con base en sus potencialidades y en su matriz cultural, para definir, explorar sus prioridades y especificidades en la búsqueda de competitividad en un contexto de rápidas y profundas transformaciones" (2005, p. 52).

De modo que, se debe concebir el desarrollo local como el empoderamiento de la sociedad local, la cual aprovechando al máximo sus potencialidades, lidera sus propios procesos de 
cambio social - mejora en la calidad de vida, creación de nuevas empresas y empleos - para insertarse en lo global de manera competitiva.

\section{Los enfoques sobre el Desarrollo Local.}

Ahora bien, surgen tres tipos de enfoques complementarios sobre el desarrollo local en la globalización "que no son necesariamente independientes unos de otros y que cobijan modalidades diferentes y sustantivas de desarrollo local, más allá de su indesmentible dimensión geográfica" (Boisier, 2005), los cuales se muestran a continuación:

\section{El enfoque como un proceso endógeno de cambio estructural.}

Garofoli define el desarrollo endógeno como "la capacidad para transformar el sistema socioeconómico; la habilidad para reaccionar a los desafíos externos; la promoción de aprendizaje social, y la habilidad para introducir formas específicas de regulación social a nivel local (...) habilidad para innovar a nivel local" (1995, p. 117).

Siendo la endogeneidad de los procesos de cambio territorial desde el plano: político, la capacidad local para tomar decisiones relevantes frente a las opciones, estilos, diseño y ejecución de políticas de desarrollo, y más que nada, a la capacidad de negociar con el entorno del territorio, es decir, ese arreglo político descentralizador; económico, la apropiación y reinversión local para diversificar la economía local, sentando las bases sustentables en el largo plazo; científico y tecnológico, la capacidad interna de un territorio organizado que genera sus propios impulsos tecnológicos de cambio, a saber, un sistema local de ciencia y tecnología; cultural, la matriz generadora de identidad socioterritorial, esa cultura local recuperada y a la vez construida (Boisier, 2005).

De modo que, los agentes locales deben tener la capacidad de transformar el entorno social y económico, enfrentar adecuadamente las externalidades, fomentar el nuevo conocimiento o aprovechar el conocimiento ya existente para innovar en la localidad. Quienes ejercen el liderazgo en los distintos ámbitos deben: decidir acertadamente en favor del desarrollo local; utilizar correctamente los recursos económicos para diversificar la economía local; fomentar la generación de conocimiento a través de la investigación y el desarrollo de tecnología que les permita innovar contantemente; y construir, recuperar y/o reforzar esa identidad local o distintivo cultural que poseen con el fin de mejorar la calidad de vida y el bienestar económico de la población local. 


\section{El enfoque como el "empoderamiento" de una sociedad local}

Para la Organización de Cooperación y Desarrollo Económicos la nueva propuesta de desarrollo local se fundamenta en la "devolución de las competencias ejecutivas a los estamentos locales"; a saber, la devolución de las capacidades hacia el ámbito local (OCDE, 2001).

Para que los territorios puedan tener éxito al competir en una economía globalizada necesitan políticas que construyan y exploten las capacidades endógenas; políticas públicas que aprovechen de mejor manera los flujos internacionales de capital y tecnología, la ampliación de mercados internaciones y de la competencia que ofrece la globalización. De las sociedades territoriales depende asumir y recuperar las competencias que les permitan intervenir en sus propios procesos de cambio social para alcanzar el desarrollo local (Boisier, 2005).

Es decir, el empoderamiento de la sociedad local que les permita explotar sus capacidades intrínsecas para tomar sus propias decisiones; recuperar sus competencias locales para intervenir y liderar sus propios procesos respecto a cómo y cuánto desarrollarse.

\section{El enfoque como matriz de estructuras industriales diversas}

Según Boisier, el enfoque de desarrollo basado en la estructura industrial "ha cristalizado en tres visiones para el análisis, la investigación y la diseminación, basadas respectivamente en i) el distrito industrial "a la italiana"; ii) el medio innovador "a la francesa", y iii) los clústers "a la americana" (2005, pp. 52-53).

Los "distritos industriales" en palabras de Ferraro: "Para Marshall, los distritos son una concentración geográfica de empresas especializadas que, aprovechando la división del trabajo en fases productivas y la especialización sectorial, consiguen ventajas de escala frente a la gran firma integrada" (2003, p. 5). De modo que, las ventajas que tienen los "distritos industriales" para alcanzar el desarrollo económico son la cercanía geográfica y la aglomeración de pymes.

Por su parte, el "medio innovador", término acuñado por economista Aydalot en el 86 y posteriormente actualizado por el GREMI, se refiere a "la capacidad que posee un determinado ámbito territorial para capitalizar la proximidad de los actores en forma de aptitudes y comportamientos orientados a la producción, transmisión y acumulación de saberes y conocimientos vinculados a la actividad productiva" (Peña, 2006). Para ello, el "medio innovador" o entorno local debe cumplir tres características: 1) un territorio sin fronteras precisas, pero unido, donde los actores se organizan, utilizan los recursos, producen e 
intercambian bienes, servicios y comunicaciones; 2) los actores que forman redes de relaciones y contacto donde establecen vínculos de cooperación e interdependencia; 3) un entorno local con procesos de aprendizaje colectivo gracias a la movilidad del trabajo en el mercado local, los intercambios de tecnología de productos, procesos, organización, comercialización, provisión de servicios especializados, flujos de información y estrategias de los actores (Vázquez, 1999).

Mientras que, los clústers son "concentraciones geográficas de empresas e instituciones interconectadas en un campo particular" (Porter, 1998). Dichas concentraciones no tienen límites geográficos definidos, por lo que posibilitan el surgimiento de actitudes empresariales, a la par, de competencia y cooperación, y permiten a los integrantes del clúster beneficiarse como si operaran a una escala mayor o como si estuvieran asociados con otros (Boisier, 2005).

Estos tres enfoques del desarrollo local - distritos industriales, medios innovadores y clústers - crean las condiciones necesarias en el entorno para que se generen procesos de desarrollo; procesos que dependerán de sociedades locales motivadas, organizadas y con conocimientos mínimos para aprovechar su potencial de desarrollo local.

\section{El potencial de desarrollo local y el rol de los Clúster}

Para comprender cómo el potencial de desarrollo local puede ser aprovechado por la creación de clústers es necesario revisar, en primer lugar, el enfoque del potencial de desarrollo local, sus conceptos y características; luego, el concepto y tipos de clústers que existen; después, la relación que existe entre clústers e innovación; para finalmente, entender como los clústers son un factor desencadenante del potencial del desarrollo local.

\section{El enfoque del potencial de desarrollo local: Concepto y características}

El enfoque del potencial de desarrollo local es aquel que "explica la existencia de un grupo de recursos con la capacidad de favorecer el desarrollo de una determinada localidad" (Almaguer, Ávila, y Pérez, 2012). De modo que, estos recursos son de vital importancia al constituirse la fuente primaria para generar el desarrollo local. No obstante, de una correcta articulación de los mismos dependerá el éxito del proceso de desarrollo.

Ahora bien, Vázquez Barquero menciona que la base del desarrollo local es "el conjunto de recursos (naturales, históricos, culturales, humanos, tecnológicos, económicos, institucionales y materiales) que constituyen su potencial de desarrollo" (1999, p. 30). Otra visión plantea que los recursos potenciales de una localidad se clasifican en varias dimensiones de recursos 
tales como: recursos físicos, recursos humanos, recursos económicos y financieros, recursos tecnológicos y recursos sociales y culturales (Alburquerque, 2002).

De acuerdo con esto, los recursos que comúnmente se pueden identificar como parte del potencial de desarrollo local se detallan a continuación en la tabla 1. 
Tabla 1. Recursos que conforman el potencial de desarrollo

\begin{tabular}{|c|c|c|c|}
\hline Recursos & Incluye & Importancia & Otras consideraciones \\
\hline Naturales & $\begin{array}{l}\text { Los elementos de la naturaleza que } \\
\text { están a disposición del hombre } \\
\text { tales como el agua, la tierra, el } \\
\text { aire, los bosques, los animales, las } \\
\text { plantas, los minerales, la geografia } \\
\text { y el clima. }\end{array}$ & $\begin{array}{l}\text { Determinan en gran medida la } \\
\text { capacidad de acción de los demás } \\
\text { tipos de recursos. }\end{array}$ & $\begin{array}{l}\text { Se convierten en potencial natural } \\
\text { cuando el hombre interactíua con } \\
\text { ellos y los utiliza en el proceso de } \\
\text { producción. }\end{array}$ \\
\hline Físicos & $\begin{array}{l}\text { Los elementos creados por el } \\
\text { hombre a partir de la } \\
\text { transformación de los recursos } \\
\text { naturales tales como las } \\
\text { infraestructuras básicas ya sean de } \\
\text { carácter material, económico, } \\
\text { social y ambiental. }\end{array}$ & $\begin{array}{l}\text { Influyen mucho en el ordenamiento } \\
\text { de una localidad mediante las } \\
\text { carácterísticas (volumen y calidad) } \\
\text { de su infraestructura. }\end{array}$ & $\begin{array}{l}\text { La infraestructura es solo una } \\
\text { condición necesaria mas no } \\
\text { suficiente, pues estimula el proceso } \\
\text { de desarrollo, pero no lo crea. } \\
\text { Una localidad con infraestructura } \\
\text { básica adecuada es más atractiva } \\
\text { para el emplazamiento de } \\
\text { actividades que benefician el } \\
\text { proceso de desarrollo local. }\end{array}$ \\
\hline
\end{tabular}

\begin{tabular}{|c|c|c|c|}
\hline Humanos & $\begin{array}{l}\text { Las personas ( } \sin \text { importar edad o } \\
\text { género) con el conjunto de } \\
\text { habilidades, capacidades, talentos, } \\
\text { experiencias y destrezas que } \\
\text { poseen y que ponen a disposición } \\
\text { del desarrollo de la localidad. }\end{array}$ & $\begin{array}{l}\text { Más que otro factor de } \\
\text { producción, son los actores } \\
\text { principales y elementales en el } \\
\text { proceso de desarrollo, pues son } \\
\text { los únicos capaces de reorientar } \\
\text { este proceso en cualquier } \\
\text { momento. }\end{array}$ & $\begin{array}{l}\text { La capacitación y preparación de } \\
\text { las personas forma parte } \\
\text { importante de estos recursos } \\
\text { porque de estas "fuerzas vivas" } \\
\text { depende en gran medida el } \\
\text { progreso de un territorio. }\end{array}$ \\
\hline $\begin{array}{l}\text { Económicos - } \\
\text { Financieros }\end{array}$ & $\begin{array}{l}\text { Las empresas, sin importar su } \\
\text { categoría o especialidad, su } \\
\text { capacidad de financiamiento, sus } \\
\text { relaciones o eslabonamientos } \\
\text { productivos y el conocimiento } \\
\text { detallado que poseen. }\end{array}$ & $\begin{array}{l}\text { El conjunto de empresas, públicas } \\
\text { o privadas, son el elemento } \\
\text { esencial porque son las unidades } \\
\text { encargadas de organizar lo } \\
\text { recursos productivos en función } \\
\text { del crecimiento económico y la } \\
\text { generación de empleo en la } \\
\text { localidad. }\end{array}$ & $\begin{array}{l}\text { Estas unidades empresariales son } \\
\text { las encargadas de aglutinar } \\
\text { coherentemente los agentes } \\
\text { productivos para estimular la } \\
\text { producción novedosa y el } \\
\text { fortalecimiento de un "entorno } \\
\text { innovador" necesario para el } \\
\text { fomento productivo local. }\end{array}$ \\
\hline $\begin{array}{l}\text { Sociales y } \\
\text { Culturales }\end{array}$ & $\begin{array}{l}\text { Las cualidades institucionales, es } \\
\text { decir, las reglas de juego de las } \\
\text { relaciones sociales de producción, } \\
\text { los valores locales, las tradiciones, } \\
\text { las normas, las organizaciones, los } \\
\text { mecanismos de asociación que } \\
\text { facilitan la interrelación dentro del } \\
\text { territorio. Así como, la cultura y la } \\
\text { identidad local. }\end{array}$ & $\begin{array}{l}\text { Las instituciones locales (reglas de } \\
\text { interación humana) tienen } \\
\text { importancia sustancial porque a } \\
\text { través de ellas se manifiestan } \\
\text { aspectos sociales como la } \\
\text { inclusión, la movilización y la } \\
\text { participación ciudadana, las cuales } \\
\text { contribuyen a movilizar el } \\
\text { desarrollo de las capacidades } \\
\text { creativas y emprendedoras de la } \\
\text { población local, potenciándolas } \\
\text { hacia ideas y propuestas } \\
\text { innovadoras. }\end{array}$ & $\begin{array}{l}\text { De la comprensión y conocimiento } \\
\text { de la cultura e identidad local se } \\
\text { desprende el uso eficiente de las } \\
\text { tradiciones, costumbres y rasgos } \\
\text { locales, de la actitud hacia las } \\
\text { innovaciones, la valoración del } \\
\text { entorno natural y el medio } \\
\text { ambiente, la existencia de } \\
\text { líderes y elites culturales, } \\
\text { económicas y políticas, la } \\
\text { valoración moral y ética ante el } \\
\text { trabajo, el } \\
\text { pago de impuestos y la } \\
\text { solidaridad. }\end{array}$ \\
\hline $\begin{array}{l}\text { Técnicos o } \\
\text { Tecnológicos }\end{array}$ & $\begin{array}{l}\text { El conocimiento tecnológico y } \\
\text { científico y la investigación } \\
\text { institucionalizada existente en una } \\
\text { localidad, no de las personas } \\
\text { como tal, sino del territorio en } \\
\text { sentido general, y que está a } \\
\text { disposición del quien pueda y } \\
\text { quiera utilizar. }\end{array}$ & $\begin{array}{l}\text { La existencia de un entorno } \\
\text { innovador y el grado de } \\
\text { introducción y difusión de esas } \\
\text { innovaciones son fundamentales } \\
\text { porque crean los canales o vías } \\
\text { para asimilar las nuevas ideas, } \\
\text { equipos y modos de organización } \\
\text { que constantemente perfeccionan } \\
\text { los mecanismos } \\
\text { de producción y gestión } \\
\text { empresarial y territorial. }\end{array}$ & $\begin{array}{l}\text { Los aspectos técnicos o } \\
\text { tecnológicos están sujetos a la } \\
\text { identificación y } \\
\text { utilización de un grupo de recursos } \\
\text { principalmente representados por } \\
\text { el conocimiento, } \\
\text { utilización y propagación de } \\
\text { tecnologías novedosas que sirvan } \\
\text { de estímulo a las actividades } \\
\text { encaminadas al desarrollo. }\end{array}$ \\
\hline
\end{tabular}


De modo que, en cada región, localidad o territorio existen distintas "estructura(s) productiva(s), mercado(s) de trabajo, factores de producción disponibles, tejido empresarial, capacidad territorial para adoptar innovaciones, capacitación del recurso humano, funcionamiento institucional, entre otros aspectos", que forman parte de su potencial y les permiten diseñar e instrumentar sus propias iniciativas locales de desarrollo (Tapia, Tapia, Moscoso, y Ortíz, 2017).

Este conjunto de recursos que conforman el potencial de desarrollo local "no constituyen elementos aislados, sino que forman parte de un sistema determinado por las interrelaciones que se producen entre ellos, a partir de las cuales se estructura el escenario local" (Almaguer, Ávila, \& Pérez, 2012). De modo que, el proceso de desarrollo local dependerá de la capacidad de los actores locales para utilizar estos recursos eficientemente.

Ahora bien, una forma eficiente con la que los agentes locales pueden gestionar estos recursos para potenciar sus procesos de desarrollo, es a través de la creación de clústers.

\section{Los clústeres: Concepto y tipos}

En los países desarrollados, los clústers desempeñan un papel importante al momento de definir políticas públicas y en cómo se relacionan las empresas para innovar y mejorar la competitividad a nivel mundial (Vera \& Ganga, 2007). De ahí que, es importante revisar las diferentes conceptualizaciones que se han dado sobre este término.

Según Michael Porter:

"Los clústers son concentraciones geográficas de empresas e instituciones interconectadas en un campo particular (...) abarcan una serie de industrias vinculadas y otras entidades importantes para la competencia. Incluyen, por ejemplo, proveedores de insumos como componentes, maquinaria y servicios, y proveedores de infraestructura especializada. (...) se extienden a menudo hacia los canales y clientes (...) a fabricantes de productos complementarios (...) empresas en industrias relacionadas por habilidades, tecnologías o entradas (...) instituciones gubernamentales y de otro tipo, como universidades, agencias de normalización, laboratorios de ideas, centros de capacitación y asociaciones comerciales que brindan capacitación especializada, educación, información, investigación y soporte técnico." (traducido del inglés por el autor) (1998, pág. 78).

Mientras que, para Joseph Ramos se entiende por clúster: 
"concentración sectorial y/o geográfica de empresas que se desempeñan en las mismas actividades o en actividades estrechamente relacionadas tanto hacia atrás, hacia los proveedores de insumos y equipos, como hacia adelante y hacia los lados, hacia industrias procesadoras y usuarias así como a servicios y actividades estrechamente relacionadas con importantes y acumulativas economías externas, de aglomeración y especialización (por la presencia de productores, proveedores y mano de obra especializada y de servicios anexos al sector) y con la posibilidad de llevar a cabo una acción conjunta en búsqueda de eficiencia colectiva" (1998, p. 108).

Por otro lado, la Organización para la Cooperación y el Desarrollo Económicos (OCDE), menciona que los clústers son:

"redes de producción de empresas fuertemente interdependientes (incluidos los proveedores especializados), vinculados entre sí en una cadena de producción de valor agregado. (...) también engloban alianzas estratégicas con universidades, institutos de investigación, servicios de negocios intensivos en conocimiento, Instituciones puentes (corredores, consultores) y clientes. (...) va más allá de las redes horizontales simples en las cuales las empresas, que operan en el mismo mercado para productos finales y que pertenecen al mismo grupo industrial, cooperan en ciertas áreas (por ejemplo, I + D conjunta, programas de demostración, marketing colectivo o política de compra conjunta). (...) son a menudo redes intersectoriales (verticales y / o laterales) y abarcan empresas complementarias especializadas en torno a un enlace específico o base de conocimientos en la cadena de valor" (traducido del inglés por el autor) (1999, p. 85).

Estas definiciones concuerdan en que los clústers se caracterizan por ser concentraciones geográficas de empresas alrededor de una actividad particular; las cuales, están vinculadas entre sí. Asimismo, reconoce la importancia de formar alianzas con instituciones que les ayuden a gestionar conocimiento para innovar y mejorar su competitividad.

De modo que, se puede definir a los clústers como concentraciones geográficas de empresas interconectadas (proveedores especializados, de servicios, empresas de sectores afines) e instituciones asociadas (por ejemplo, gobierno, universidades, centros de investigación, instituciones financieras e instituciones de asociación) en un campo particular; que compiten, pero que a la vez cooperan entre sí, generando el conocimiento necesario, a través de la investigación y desarrollo (I+D), para innovar en el proceso productivo y mejorar su competitividad. 
En cuanto a la tipología de los clústers existen distintas formas de clasificarlos. A continuación, en la tabla 2 se resumen algunas de ellas:

Tabla 2. Tipología de clústers según diferentes perspectivas

\begin{tabular}{llllll}
\hline Sectores & $\begin{array}{l}\text { Organización } \\
\text { industrial }\end{array}$ & $\begin{array}{l}\text { Dinámica de } \\
\text { funcionamiento }\end{array}$ & $\begin{array}{l}\text { Naturaleza de } \\
\text { la empresa y } \\
\text { sus relaciones }\end{array}$ & América Latina \\
\hline Alta tecnología & $\begin{array}{l}\text { Cadena de valor } \\
\text { o verticales }\end{array}$ & $\begin{array}{l}\text { En pleno } \\
\text { funcionamiento }\end{array}$ & $\begin{array}{l}\text { Aglomeración } \\
\text { pura }\end{array}$ & Sobrevivencia \\
$\begin{array}{l}\text { Tipos de } \\
\text { clústers }\end{array}$ & Industriales & $\begin{array}{l}\text { Basados en } \\
\text { competencia u } \\
\text { horizontales }\end{array}$ & Latentes & $\begin{array}{l}\text { Complejo } \\
\text { industrial }\end{array}$ & $\begin{array}{l}\text { Producen para el } \\
\text { consumo masivo }\end{array}$ \\
& Servicios & & Potenciales & $\begin{array}{l}\text { Redes sociales } \\
\text { de trabajo }\end{array}$ & $\begin{array}{l}\text { Proveedores de } \\
\text { las empresas } \\
\text { transnacionales }\end{array}$ \\
\hline
\end{tabular}

Fuente: Elaboración propia.

Para Porter, se pueden clasificar los clústers según el sector en que se desarrollan y su organización industrial. De modo que, los clústers "surgen tanto en sectores de alta tecnología como en sectores tradicionales, tanto en sectores industriales como en sectores de servicios. Algunas regiones tienen un único clúster dominante, mientras que otras tienen varios" (Porter, 2003, pág. 213). Asimismo, los clústers pueden ser verticales, "aquellos que reúnen industrias caracterizadas por relaciones de compra-venta"; u horizontales, aquellos que "incluyen empresas que comparten un mercado común para los bienes finales, o utilizan la misma tecnología o trabajadores, o requieren un recurso natural similar" (Porter, 2003, p. 205). Primando, en los clústers verticales las relaciones de cooperación y colaboración, mientras que en los horizontales la rivalidad y la competencia (Bao y Blanco, 2014).

Para Bao y Blanco, citando a Michael Enright (1996), los clústers se clasifican según su dinámica de funcionamiento en: pleno funcionamiento, aquellos con buen conocimiento propio y capaces de alcanzar su pleno potencial, produciendo más que la suma de sus partes, que cuentan con infraestructura social muy fuerte, con información que fluye continuamente, que proponen nuevas ideas, generan colaboración entre las compañías y fomentan el arranque de nuevas empresas; latentes, aquellos que cuentan con oportunidades, pero que no han sido explotadas y aún no han alcanzado sinergias, su infraestructura social es de carácter medio, que no reúne todos los condicionantes deseados (flujo de información, colaboración o falta de visión común) que faciliten enfrentar a la competencia exterior; y potenciales, aquellos clústers que cuentan con algunos requerimientos, pero les falta masa crítica y/o condiciones o inputs, 
que tienen una infraestructura social bastante débil y les falta mucho camino por recorrer en su intento de convertirse en clústers (2014, pp. 183-184).

Otra clasificación reciente es aquella basada en la naturaleza de las empresas y sus relaciones, siendo: aglomeración pura, complejo industrial y red de trabajo social lammarino \& McCann (2006). Entendiéndose: por aglomeración pura, al conjunto de empresas muy pequeñas y sin poder de mercado, cuyas relaciones con otras empresas y consumidores cambian constantemente según las oportunidades que presente el mercado, con intensa competencia local, deslealtad y relaciones a corto plazo; por complejo industrial, al grupo de compañías con relaciones estables, predecibles y a largo plazo, siendo la proximidad necesaria para minimizar los costes de transporte de las transacciones habituales entre ellas; y por redes sociales de trabajo, a las empresas con cultura de confianza y lealtad que les permiten emprender acciones conjuntas, compartir riesgos, realizar alianzas y acuerdos recíprocos basados en relaciones comerciales (Bao y Blanco, 2014, pp. 184-185).

Finalmente, Altenburg y Meyer-Stamer (1999) proponen una tipología de clústers para América Latina: los de sobrevivencia, los que producen para el consumo masivo y los proveedores de empresas transnacionales. Siendo los de sobrevivencia los formados por pequeñas empresas con producción de consumo de baja calidad para mercados locales, menor grado de especialización y poca cooperación entre ellos, así como una baja especialización de mano de obra; los que producen para el consumo masivo los formados por medianas y grandes empresas cuya producción la destinan al mercado nacional, cuentan con buena organización administrativa y capacidad tecnológica, pero con escasa innovación tecnológica, salvo de sus proveedores quienes le proveen maquinaria automatizada con tecnología de punta; y los proveedores de empresas transnacionales que realizan actividades tecnológicas más complejas, como por ejemplo el ensamblaje y fabricación de piezas para la industria electrónica y automotriz. Usualmente quienes abastecen a estas empresas están conectadas con los mercados globalizados (Corrales, 2007, pp. 190-191).

\section{Clúster, Innovación y Desarrollo local}

Para Schumpeter, la innovación surge cuando: a) se introduce nuevos bienes de consumo en el mercado o cuando se mejora la calidad de los mismos; b) se introduce nuevos métodos o formas de producir bienes o hacer las cosas; c) se apertura un nuevo nicho de mercado; d) se consigue una nueva fuente de provisión de materias primas; y e) realizan cambios dentro de la organización de las organizaciones o en sus procesos de gestión (Schumpeter, 1978). De hecho, llega a considerar al proceso de innovación tecnológica (invención), como la fuerza 
fundamental que causa los procesos de transformación constante, a saber, el desarrollo económico (Schumpeter, 1996).

Por su parte, la OCDE y la Oficina Europea de Estadísticas (Eurostat) publicaron el Manual de Oslo en 2005, donde caracterizan a la innovación como aquella que: "a) está asociada a la incertidumbre; b) implica inversión en bienes materiales y no materiales; c) está sometida a los desbordamientos tecnológicos; d) implica el uso de un nuevo conocimiento o un nuevo uso o combinación de conocimientos existentes; y e) tiene como objetivo la mejora de la empresa y de su capacidad competitiva" (Becerra y Naranjo, 2008).

De modo que, innovar es crear valor a través de nuevo conocimiento o por nuevas formas de usar el conocimiento ya existente para producir nuevos bienes o servicios, nuevas formas de negocio, otras formas organizativas y/o estructuras organizacionales.

Y aquí podría agregarse a los clústers como el ámbito propicio para la innovación porque, como indica Porter, "los clústers juegan un papel vital en la capacidad progresiva de una compañía para innovar" debido a factores como: los "compradores sofisticados" que son fuente de información valiosa sobre tecnologías y mercados emergentes; los "proveedores especializados" que permiten altos niveles de flexibilidad y rapidez para introducir innovaciones; el apoyo entre las empresas y la rivalidad entre competidores, que fomentan la investigación y desarrollo (I+D) y facilitan la introducción de nuevas estrategias y técnicas (Porter, 1998).

Asimismo, los clústers potencian las innovaciones a causa de los desbordamientos tecnológicos, el mercado laboral local y la cooperación (Brenner \& Greiff, 2006). Además, gracias a la proximidad, la confianza, la rivalidad y los acuerdos de subcontratación, las nuevas tecnologías se difunden rápidamente (Khan \& Ghani, 2004).

De modo que, con base en lo anterior, es importante resaltar que el clúster y la innovación están muy ligados, ya que el primero (clúster) constituye el entorno favorable para innovar, y cuando esta innovación sucede dentro de él, lo obliga a innovar para adaptarse a los constantes cambios producidos.

Los clústers benefician a las economías pues generan desarrollo económico local. Las concentraciones geográficas de empresas interconectadas e instituciones asociadas en un campo particular pueden cooperar entre sí, sin importar su tamaño, y generar eficiencia colectiva, mientras compiten por el mercado local (Porter, 1998). 
Esta interacción entre ellas, fomenta la innovación y genera investigación y desarrollo $(I+D)$, lo cual produce mayor productividad al introducir nuevos bienes y/o servicios, al crear nuevos negocios o por la expansión y crecimiento de los ya existentes (Porter, 1998). Asimismo, al mejorar la calidad de los productos y/o servicios aumenta la competitividad local y brinda la oportunidad de insertarse a la globalización.

De modo que, las empresas al ser más productivas generan mayor rentabilidad, y esto resulta en mejores salarios, lo cual produce un aumento en la calidad de vida y en el bienestar económico de los habitantes donde funciona dicho clúster.

A continuación, se muestra cómo los clústers potencian el desarrollo económico local:

Figura 1. Clúster como potenciador del desarrollo local

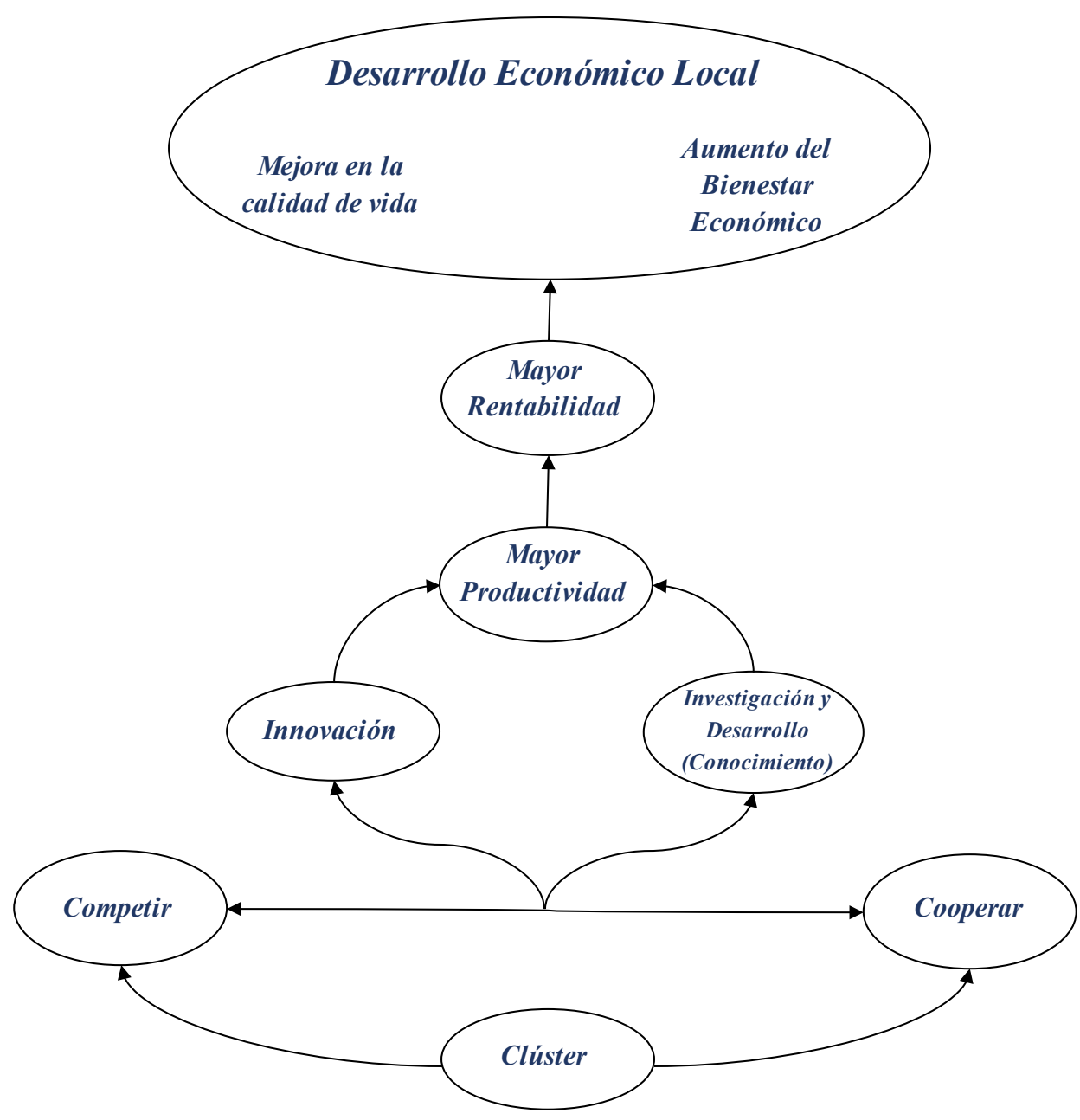

Fuente: Elaboración propia. 


\section{CONCLUSIONES}

Los fundamentos teóricos analizados demuestran que para que una localidad, región o territorio alcance el desarrollo económico debe aprovechar su potencial endógeno, el cual está conformado por los recursos internos con los que cuenta. Una forma de conjugar estos recursos a fin de aprovechar aquellos que tienen potencial, neutralizar los que causan limitaciones y enfrentar a los que ocasionan problemas, es a través de los clústers; es decir, aquellas aglomeraciones de empresas e instituciones vinculadas que al competir y cooperar entre sí generan el conocimiento necesario que les permite innovar para mejorar su productividad y aumentar su rentabilidad.

El Ecuador del siglo XXI tiene como reto implementar las estrategias que sean necesarias para aprovechar el potencial de desarrollo con el que cuenta cada localidad; de manera que, se empiece a operar a modo de clúster alrededor de un producto o servicio típico de cada cantón, con el fin de que las economías locales transiten por los sectores terciario y cuaternario, y ya no dependan solamente de los sectores primario y secundario. Los clústers que puedan crearse en cada localidad, territorio o región del Ecuador potenciarán el desarrollo económico; es decir, la mejora de la calidad de vida y el aumento del bienestar económico de la población ecuatoriana.

\section{REFERENCIAS BIBLIOGRÁFICAS}

Alburquerque, F. (2002). Desarrollo económico territorial. Sevilla, España: Ed. Instituto de Desarrollo Regional. Fundación Universitaria.

Alcañiz Moscardó, M. (2008). El desarrollo lo cal en el contexto de la globalización. Convergencia Núm. 47 , 285-315.

Almaguer, D., Ávila, A., y Pérez, M. (2012). El potencial de desarrollo local y las ventajas de su visión desde una perspectiva de redes. Observatorio Iberoamericano del Desarrollo local y la economía social Año 6 No. 12.

Altenburg, T., \& Meyer-Stamer, J. (1999). How to Promote Clusters: Policy Experiences from Latin America. World Development, vol. 27, núm. 9. 
Bao, S., y Blanco, F. (2014). Modelos de formación de clústers industriales: revisión de las ideas que los sustentan. Revista Galega de Economía, vol. 23, núm. 2, 179198.

Becerra, F., \& Naranjo, J. (2008). La innovación tecnológica en el contexto de los clusters regionales. Cuadernos de Administración, vol. 21, núm. 37, 133-159.

Boisier, S. (2005). ¿Hay espacio para el desarrollo local en la globalización? Revista de la CEPAL $86,47-62$.

Brenner, T., \& Greiff, S. (2006). The dependence of innovativeness on the local firm population-An empirical study of German patents. Industry and Innovation, 13 (1), 21-39.

Buarque, S. (1999). Metodología de planejamento do desenvolvimento local e municipal sustentable. Recife, Brasil: Instituto Interamericano de Cooperación para la Agricultura (IICA).

Casanova, F. (2004). Desarrollo lo cal, tejidos productivos y formación. CINTERFOR, 26.

Cividanes, J. (2002). El territorio como variable económica: el concepto de sistema productivo local. $V$ Jornadas de Economía Crítica. Barcelona.

Corrales, S. (2007). Importancia del cluster en el desarrollo regional actual. Frontera Norte, vol. 19, núm. 37, 173-201.

Enright, M. (1996). Regional Clusters and Economic Development: A Research Agenda. Business Networks: Prospects for Regional Development.

FERRARO, C. (2003). Estudio 1.eg.33.3 estudios sobre empleo componente b: desarrollo productivo local en argentina. Buenos Aires.

Garofoli, G. (1995). Desarrollo económico, organización de la producción y territorio. Desarrollo económico local en Europa, 113-123.

lanmarino, S., \& McCann, P. (2006). The Structure and Evolution of INdustrial Clusters: Transactiones, Technology and Knowledge Spillovers. Research Policy, 35 (7), 1018-1036. 
Khan, J., \& Ghani, J. (2004). Clusters and entrepreneurship: Implications for innovation in a developing economy. Journal of Developmental Entrepreneurship, 9 (3), 221 238.

León Segura, C., \& Peñate López, O. (2011). Territorio y desarrollo local. Economía y Desarrollo vol. 146, núm. 1-2, 5-18.

Moreno, L. (2009). Oportunidades de financiamiento para los entes locales en el siglo XXI. Recuperado de http://www.eumed.net: www.eumed.net/libros/2009c/596/

OCDE. (2001). Devolution and Globalisation: Implications for Local Decision-makers. Paris.

Organización Internacional del Trabajo. (08 de 05 de 2019). Recuperado de https://www.ilo.org/: https://www.ilo.org/empent/areas/local-economic-developmentled/lang--es/index.htm

Organización para la Cooperación y el Desarrollo Económicos (OCDE). (1999). Managing National Innovation Systems. 85-89.

Peña Sánchez, A. (2006). Las disparidades económicas intrarregionales en Andalucía. La tesis del "entorno innovador" o los "milieux innovateurs". Recuperado de http://www.eumed.net/tesis-doctorales/2006/arps/1s.htm

Porter, M. (1998). Clusters and the new economics of competition. Harvard Business Review vol. 76 No. 6, 77-90.

Porter, M. (2003). Ser competitivo: nuevas aportaciones y conclusiones. Bilbao: Ediciones Deusto.

Ramos, J. (1998). Una estrategia de desarrollo a partir de los complejos productivos en tornoa los recursos naturales. Revista CEPAL 66, 105-125.

Schumpeter, J. (1978). Teoría del desenvolvimiento económico. Quinta Reimpresión. México: Fondo de Cultura Económica.

Schumpeter, J. (1996). Capitalismo, socialismo y democracia. T.I. Barcelona: Ediciones Folio.

Silva Lira, I. (2003). Disparidades, competitividad territorial y desarrollo local y regional en América Latina. CEPAL - SERIE Gestión Pública No. 33, 46. 
Stiglitz, J. (2002). El malestar en la globalización. Madrid: Editorial Taurus.

Tapia, E., Tapia, S., Moscoso, J., \& Ortíz, H. (2017). Economía solidaria: estrategia alternativa para el desarrollo local. Visión gerencial No. 2, 313-323.

Vázquez Barquero, A. (1999). Desarrollo, redes e innovación: lecciones sobre desarrollo endógeno. Madrid: Ediciones Pirámide.

Vera, J., \& Ganga, F. (2007). Los clústers industriales: precisión conceptual y desarrollo teórico. Cuad. Adm. Bogotá, 303-322. 